\title{
Differenz
}

Revista internacional de estudios heideggerianos y sus derivas contemporáneas

AÑO 6 NÚMERO 5: JULIO DE 2019. e-ISSN: 2386-4877 - DOI: 10.12795/DIFFERENZ.2019.I05.04

[pp. 73-89]

Recibido: 03/02/2019

Aceptado: 25/06/2019

\section{El poema y la esencia del habla. En torno a los escritos heideggerianos de la década de 1950.}

\section{The poem and the essence of speech. Around the Heideggerian Writings of the 1950s}

\author{
Paula Sánchez Mayor \\ Universidad Complutense de Madrid
}

\section{Resumen:}

Este artículo tiene como objetivo profundizar en la relación que en la filosofía heideggeriana tienen las nociones de "poema" y "habla". Para ello se realiza un estudio de la obra más representativa a este respecto, De camino al habla, y se analiza el vínculo que esta obra tiene con las nociones de "esencia de la verdad" y "esencia del habla".

Palabras clave: Habla; Poema; Esencia; Lenguaje; Camino.

\section{Abstract:}

This article aims to deepen the relationship between the notions of "poem" and "speech" in Heideggerian philosophy. In order to do so, a study is made of the most representative 
work in this regard, On the way to Lenguaje, and the link that this work has with the notions of "essence of truth" and "essence of speech" is analyzed.

Keywords: Speech; Poem; Essence; Languaje; Way.

\section{Introducción.}

Este trabajo tiene por objeto ofrecer un primer acercamiento a la reflexión heideggeriana en torno a la esencia del habla. Hemos acotado tal reflexión a los escritos de la década de 1950 recogidos en De camino al habla. En el desarrollo del trabajo se espera mostrar el poema como el sendero que guía a los hablantes en la dilucidación de la esencia del habla. En el transcurso del trabajo se verá cómo Heidegger trastoca la vieja idea de que la obra de arte, el poema, sea representación, bien de la naturaleza exterior, bien de los sentimientos interiores del artista. El poema como esencia del habla es apertura de sentido y por ello origen en cuanto que permite y sostiene la brecha en la que las cosas vienen a ser.

En el habla cotidiana se usa el lenguaje como instrumento, como un utensilio para comunicarse. Tradicionalmente el lenguaje ha sido considerado sólo en este aspecto, como mero instrumento para comunicarnos, ya que se entiende que el lenguaje recoge con palabras las cosas que ya están ahí puestas. Heidegger propone volver a pensar el lenguaje, esta vez atendiendo a la esencia del habla. Cada vez que se intenta mentar la esencia del habla se cae de nuevo en la opinión corriente según la cual el habla es un sistema de signos fonéticos que remiten a las cosas, es decir, se cae de nuevo en la vieja explicación aristotélica. Heidegger tratará de ver la esencia del habla como habla de la esencia, trasladándola así al estatuto originario que le pertenece en tanto que apertura de sentido. Recorrer el camino hacia la esencia del habla será una tarea que sólo pueden llevar a cabo los hombres gracias a que ya están siempre, de alguna manera, en el habla.

El punto de llegada será exponer que el poema cobija la esencia del habla debido a que, en él, el son del silencio se hace perceptible a los mortales, que pueden así corresponder al habla en la escucha, siendo la escucha de esta manera previa y constituyente del hablar mismo.

\section{El camino}

La propuesta de Heidegger es dilucidar el habla, dilucidar en el sentido de arrojar luz. Arrojar luz al camino que se recorre, arrojar luz al suelo sobre el que se está caminando 
en la búsqueda de la esencia del habla. Se trata de un camino largo y tortuoso, a veces peligroso $^{1}$, ya que no hay más remedio (aunque por lo menos hay este remedio) que recorrerlo con la ayuda de aquello mismo sobre lo que se pregunta. Esto da miedo, ya que siempre cabe la posibilidad de que aquello que se intenta alcanzar se escape porque el propio medio que hay para llegar a ello lo impida. Pero no se puede dilucidar el habla si no es hablando, aun así hay que tener siempre presente que no se busca el habla que hablan los mortales, sino el habla del habla. Por tanto el círculo que en un primer momento desanimaba a llevar a cabo esta empresa se muestra ahora como un círculo inevitable, como la única manera de llegar a la meta, o, como el caminante de Trakl, a casa. "No queda más remedio que recorrer todo el círculo"2. Como hablantes los mortales tienen la misión de andar este camino, porque si el habla es la morada de la existencia del hombre, se trata de una misión que impele y que no puede dejar indiferente. Los hombres se juegan la existencia en este camino, porque: "solamente el habla capacita al hombre ser aquel ser viviente que, en tanto que hombre, es" ${ }^{\prime 3}$.

Si dilucidar el habla de esta manera implica al hombre hasta tal punto, habrá que ver esta aventura como una experiencia. Heidegger habla de hacer una experiencia con el habla, y se refiere justamente a que la relación del hombre con el habla ha de ser tal que le acaezca, que le involucre en lo más íntimo. Llega a decir que el camino de-manda, Ilama $^{4}$ a que se recorra porque alcanza a la esencia del hombre, que debe llegar a donde pertenece, esto es, como hemos dicho, al habla. "El camino nos deja llegar a lo que nos de-manda y en cuyo ámbito ya nos hallamos"5. Se presenta así el habla como el hogar de la esencia del hombre; pero hogar en el más profundo de los sentidos, como aquello que resguarda y que conforma lo que recoge en su seno. El camino de-manda al hombre a que lo recorra; pero no se trata de un camino previamente indicado y construido, sino que en el mismo caminar se hace el camino. En-caminar es "dotar la región de caminos" ${ }^{\text {. En }}$ el momento en el que el hombre se pone en camino abre el camino, como el explorador abre camino en la vegetación tupida de la Selva Negra.

1 Cfr. HEIDEGGER, M. “De un diálogo del habla (1953/54)" en De camino al habla. Barcelona, Serbal, Barcelona, 2002.

2 HEIDEgGER, M., "El origen de la obra de arte (1935/36)" en Caminos de bosque. Madrid, Alianza, 2010. p. 12.

3 HEIDEGger, M. "El habla (1950)" en De camino al habla, Op. cit, p. 9.

4 Giani Vattimo aclara que "el lenguaje es ante todo,y más originariamente que una facultad de la que disponemos, un 'dirigirse a nosotros' sin el cual no podríamos hablar" (VATTIMO, G. Introducción a Heidegger. Barcelona, Gedisa, 1998. p. 114).

5 HEIDEGGER, M., "La esencia del habla (1957)”, en De camino al habla.Op. cit. p. 148. 6 lb. p. 146. 
Pero esto no ocurre en el habla cotidiana. De hecho, habría incluso que reservarse de llamar habla a lo que no es sino cháchara; para matizar esto Heidegger comienza a utilizar la palabra Sage, que en español podemos traducir por "Decir". Se trata, en todo caso, de llamar la atención sobre el hecho de que la dilucidación no tiene por objeto el hablar corriente que usamos a diario sólo como instrumento para comunicarnos, sino que queremos adentrarnos en algo más originario, que, sin embargo, no deja de ser la condición de posibilidad para esa cháchara. Pero, a pesar de ello, no podemos buscar la esencia del habla en el habla cotidiana ya que allí se nos escapa, se nos escurre. En la cháchara podemos alcanzar el objeto del que estamos hablando, pero no el hablar mismo, no el hablar del habla.

Al "hablar del habla" Heidegger lo denomina en ocasiones como "lo hablado puro", y lo define de la siguiente manera: "aquel donde la perfección del hablar, propio de lo hablado, se configura como perfección iniciante"7. Es decir, Heidegger está buscando dónde se muestra el hablar del habla. Inevitablemente, debe ser en alguno de los modos que tiene el hombre de hablar, pero ha de ser uno peculiar ya que casi nunca se da. Tiene que ser un modo de hablar del hombre en el que se deje mostrar la esencia del habla. No comprenderemos por qué Heidegger elige "lo hablado puro" hasta que no veamos qué es la esencia del habla. De momento podemos, y es necesario, adelantar que lo hablado puro es el poema. De esto nos encargaremos en el siguiente apartado.

\section{La esencia del habla: el habla de la esencia}

Se trata, con Heidegger, de dilucidar el lugar, el lugar mismo en el que el hombre se encuentra como hablante. Esto es el lugar del habla, no es la primera vez que veremos el habla en un contexto local o espacial, ya que también aparece en ocasiones como morada8. Hay que entender el lugar tal y como lo hace Heidegger, en el sentido de aquello que recoge, reúne y resguarda, dejando, sin embargo, traslucir lo reunido para liberar su ser propio. Ese lugar es en el que se puede alcanzar a comprender la esencia del habla, ese lugar es "lo hablado puro": "si debemos buscar el hablar del habla en lo hablado, debemos encontrar un hablado puro en lugar de tomar indiscriminadamente un hablado cualquiera" 9 .

7 HEIDEGGER, M., "El habla", op. cit., p. 12.

8 "El lenguaje es la casa del ser. En su morada habita el hombre". HeIDEgGer, M., "Carta sobre el humanismo (1940)", en Hitos, Madrid, Alianza, 2000, p. 259.

9 HEIDEGGER, M., “El habla”. op. cit, p. 12. 
Heidegger halla "lo hablado puro" en el poema: "un hablado puro es aquel donde la perfección del hablar, propio de lo hablado, se configura como perfección iniciante. Lo hablado puro es el poema"10. Que lo hablado puro sea el poema significa que el camino de la dilucidación y la experiencia del hablar tiene que recorrerse de la mano de la poesía. Ya se ha dicho que, tanto el camino como la meta, son lo mismo: el habla. Pero, además se trata de un camino en el que el hombre ya siempre está, porque el hombre es tal en tanto que hablante. Sin embargo, se ha visto que no cualquier "hablar" es válido para el propósito y se ha adelantado la conclusión de que es en el poema donde se debe ir a buscar. Para entender por qué esto tiene que ser así, hay que tener presente que Heidegger se desmarca de la tradición que entiende el poema como expresión de los sentimientos interiores del poeta; es decir, deja atrás una estética de la subjetividad.

Lo que ocurre en el poema no es, para Heidegger, la expresión de la subjetividad del poeta, sino que: "en un poema el poeta imagina algo que puede ser y estar en su presencia"11. A partir de aquí se puede estudiar cómo lo que que acaece en el poema es justo eso, un acaecer, un suceder, un venir a ser. El hablar del poema lo que hace es "nombrar": "este hablar nombra la nieve que cae sin ruido en la ventana en el día que declina mientras la campana de la tarde resuena"12. Relacionado con ese "estar en su presencia", el nombrar es traer a presencia, llamar lo que no es para que venga a ser. Dicho de otra manera, el venir a ser se da en el nombrar como un llamar a las cosas a la presencia. El nombrar abre el claro en el que vienen a ser los entes en la relación con los mortales. En la época en que pronuncia las conferencias que integran De camino al habla, Heidegger ya ha escrito De la esencia de la verdad, De la esencia del fundamento y El origen de la obra de arte; y, aunque se ha alejado de varios términos e ideas que ahí aparecen, será muy importante ver cómo estos textos se entrelazan, ya que en De camino al habla la esencia del habla va a dejarse ver como un mostrar y traer a la apertura lo ente para que así sea aquello propio que es.

Por eso, y en íntima vinculación con el poema como nombrar, está la idea de matizar ese nombrar acompañándolo del término "invocar". El poema es el nombrar invocador: "el nombrar invoca"13. En "invocar" resuena "evocar aquí", es una llamada en el sentido de traer, pero ¿qué trae el poema? Lo llamado en el poema mismo. Cuando el poeta nombra la nieve la trae a presencia, pero de tal forma que no ocupa lugar, es una presencia en

$10 \mathrm{lb}$.

$11 \mathrm{lb}$. p. 14.

12 lb. p. 15.

$13 \mathrm{lb}$. 
tanto que venir a ser, no venir a un lugar físico, sino a la relación con el poeta y con sus oyentes. Invocar es dar lugar a una apertura de sentido. La relación a la que llama el poeta a las cosas es una relación que se da sobre una apertura de sentido. Si en este punto nos fijamos en cómo explica Heidegger el venir a ser en De la esencia de la verdad, vemos que tiene lugar siempre sobre un fondo, un vacío, un abismo que no deja de ser condición para el venir a ser. Ese abismo es explicado como retirada del ser para dejar ser a lo ente aquello ente que es. En el poema la invocación llama a "una presencia que resguarda la ausencia"14. En esta lógica de una ausencia que resguarda la presencia, de una ocultación que sostiene la desocultación, está la clave para que el poema sea lo hablado puro. Sin embargo debe precisarse que aunque en De la esencia de la verdad y en De camino al habla Heidegger esté desplazando la identidad en el origen, en cada texto está tratando con ámbitos distintos. Más adelante terminaremos de matizar esta cuestión.

Tomando pie en un verso de Stefan George Heidegger va a seguir aproximándose a la esencia del habla. "Ninguna cosa sea donde falta la palabra" ${ }^{15}$, se trata de un verso que da, regala, la posibilidad de comprender la esencia del habla. La esencia del habla se presenta como aquello que da ser a la cosa. Este "dar" (geben), tiene que entenderse como una donación. En una donación no hay contraprestación, donar produce un desequilibrio que no puede ser compensado. La donación moviliza una arbitrariedad radical porque el don no es necesario y por ello transgrede la lógica del equilibrio, es algo de más que no se espera y que no se necesita. En este sentido es como se entiende que la palabra "da" (es gibt) ser a la cosa. En el dar ser, la palabra, por ser aquella que "da", nunca está ella misma dada. Hay que pensar aquí, de nuevo, en el juego de presencia/ausencia. La palabra está en la situación de dar, no de ser, "la palabra, el decir, no tiene ser"16; está en la misma situación que el "es". Ambos, en la medida en que dan ser, no pueden al mismo tiempo ser algo o estar dados porque en lo dado se retira el darse.

Al encontrarse en la situación de dar ser pero no estar ella misma dada, para Heidegger:

la palabra revela otro más alto reino. No es ya meramente un asir que confiere nombre a lo presente ya representado; no es solamente un medio de representación de lo que está ante nosotros. Al contrario: es sólo la palabra la que otorga la venida en presencia, es decir, aquello en que algo puede aparecer como ente ${ }^{17}$.

14 lb. p. 16.

15 Citado por heIDEgGer, M. "La esencia del habla", op. cit., p. 121.

16 HEIDEGGER, M., "La esencia del habla”, op. cit., p. 142.

17 HeIDEgGeR, M., "La palabra (1958)", en De camino al habla. Op. cit. p. 168. 
Este aparecer como ente se traduce por dejar ser una cosa como cosa, dejar ser a algo aquello que es. En alguna ocasión Heidegger habla de Bedingnis, "en-cosamiento", para referirse a cómo la palabra en-cosa, deja ser cosa, a la cosa misma. Por tanto, ahora se aprecia que ese "dar ser" es un dejar ser, permitir que la cosa sea la cosa que es. Pero permitir no como dar permiso, no como quitar prohibiciones, sino como posibilitar, abrir el claro de sentido que salvaguarda la relación en la que las cosas vienen a ser cosas. Es un dejar ser que va siempre acompañado de un comprometer.

El "dar ser" de la palabra del poema es abrir el sentido, ahora hay que explicar este "abrir". Se trata de una apertura como una raja, una brecha, una fractura que deja un espacio vacío en medio. Por eso dice Heidegger en El camino al habla: "la unidad de la esencia del habla buscada la llamaremos der Aufriss, el trazo abriente"18. En el trazo abriente se despliega el habla como estructura del mostrar en la que se da la relación entre el hablante y su hablar y entre lo hablado y lo inhablado, porque recordemos que lo no hablado forma parte intrínseca del hablar. En esta misma conferencia Heidegger define el trazo abriente como lo abierto libre del habla. Y no por casualidad la libertad entra aquí en juego, ya que si recordamos las conferencias que antes hemos mencionado De la esencia de la verdad y De la esencia del fundamento, veremos cómo la libertad juega un papel fundamental ${ }^{19}$ :

La libertad respecto a lo manifiesto de un ámbito abierto permite que el ente sea siempre ese ente que precisamente es. La libertad se desvela ahora como un dejar ser a lo ente ${ }^{20}$.

Una vez vista la relación entre el habla y la libertad, en tanto que ambas son la posibilidad del venir a ser de las cosas, no es extraño que Heidegger elija el verbo alemán sagen (Decir) en lugar de sprechen (hablar) ya que el primero connota los rasgos de mostrar, dejar aparecer, incluso dejar ver y oir.

Atendamos al carácter de rajadura o fractura de la apertura de sentido del trazo abriente que es la esencia del habla (Decir). Se trata de una fractura relacional que es ya la Diferencia. Introducir diferencias, dejar espacio para las diferencias es la única manera de que los entes sean aquello que son, y no se confundan con otros en un fondo común indeterminado. Que algo sea eso mismo que es, supone que no es ninguna de las otras cosas que son.

18 HEIDEGGER, M., "El camino al habla (1959)", en De camino al habla. Op. cit. p. 187

19 Aquí fundamental debe entenderse tanto lo principal como lo que da fundamento (pero no suelo firme).

20 HeIDEgGer, M., “De la esencia de la verdad (1943)”, en Hitos. Op. cit. p. 159 
La diferencia para mundo y cosa hace advenir la cosa a su ser propio (ereignet) en el gestar configurativo del mundo, hace advenir a su ser propio el mundo en el consentimiento de $\operatorname{cosas}^{21}$.

La Diferencia va a ser determinante en el venir a ser de los entes. El Decir abre el sentido sobre el abismo de la Diferencia. La Diferencia moviliza una fractura dolorosa y a la vez una relación. Fractura porque no hay completitud en el origen y relación porque no hay autonomía ni sustancialidad previa. Las cosas vienen a ser en la relación con los hablantes, y no hay nada previo unitario que confiera ser a las cosas. En el origen está ya la pluralidad porque el origen es relacional, no único, y además se da sobre un fondo abismal, no sobre un sustrato unívoco. No hay nada previo a la relación en la que los entes vienen a ser.

Se trata así de una fractura porque nunca hay completitud en la apertura de sentido. Nunca hay completitud ni autonomía y esto se debe a que el salto del no ser al ser es una donación, como hemos dicho antes, un desequilibrio sin retribución ante el que uno está indefenso y que por ello descoloca. La fractura es tal porque es desinteresada, rompe el orden establecido para dejar hueco a algo nuevo e inesperado. Hemos utilizado los términos "fractura" y "rajadura" para destacar el aspecto doloroso de la apertura del claro de sentido. No se trata del dolor humano, sino más bien hace referencia al desgarro de separar para dar lugar a la Diferencia del venir a ser de las cosas. "El dolor desgarra desjuntando; separa, pero de modo que, al mismo tiempo, reúne todo en sí"22.

Para terminar de hacernos cargo del habla como apertura de sentido podemos ver la semejanza entre estas dos frases de Heidegger: "La esencia de la verdad es la verdad de la esencia"23 y "La esencia del habla: el habla de la esencia" ${ }^{24}$.

Tradicionalmente la esencia de algo es aquello que le hace ser lo que es, el substrato que permanece frente a todos los cambios y que por ello le da identidad a la cosa. En este caso, para Heidegger esencia debe entenderse más bien como el fundamento de la posibilidad de que algo sea lo que es. En la primera nota a la tercera edición que aparece en "La esencia de la verdad", vemos: "esencia: 1. quidditas-el qué es-Koıvóv; 2. posibilitacióncondición de posibilidad; 3 . fundamento de la posibilitación"25.

21 HEIDEGgER, M., "El habla". op. cit, p. 19.

22 Ib. p. 20.

23 HEIDEGGER, M., "De la esencia de la verdad". Op. cit. p. 170.

24 HeIDEgGER, M., “La esencia del habla”, op. cit., p. 148.

25 HEIDEGGER, M., “De la esencia de la verdad”. op. cit. p. 151. 
Si recordamos la caracterización de la verdad propuesta por Heidegger recurriendo al

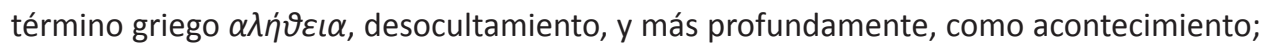
se trata del acontecimiento de venir algo a lo propio mediante el aparecer. Por tanto, cuando Heidegger hace el giro en la primera frase, lo que está haciendo es dejar de preguntarse por lo que permanece en la verdad, para mostrar la verdad como acontecimiento y la esencia como fundamento de la posibilidad de que algo sea. Lo que posibilita la verdad, es el desocultamiento de lo ente. Pero, como ya se ha dicho más arriba, el desocultamiento se da siempre sobre una ocultación, o, más bien íntimamente acompañado de una ocultación, de una ausencia constitutiva de la presencia.

En la segunda frase el habla se está entendiendo con la palabra alemana Sagen, Sagan, (Decir), y significa mostrar en tanto que "dejar aparecer; liberación luminosaocultadora" ${ }^{26}$. Esta frase sirve a Heidegger de frase rectora a la hora de dilucidar el habla. En ambos textos se está definiendo de manera paralela la verdad y el habla. Hasta el punto de que se podría decir que la apertura del claro donde los entes vienen a ser, es decir, donde se muestran en tanto que se desocultan, tiene lugar en el habla. Aun así, se debe de nuevo remarcar que la primera frase se enmarca en una reflexión ontológica y la segunda en una reflexión sobre el habla. Aunque ambas operan desde la no identidad en el origen, cada una lo hace de manera diferente, y este paralelismo debe servir de guía inicial pero no debe confundirse cada ámbito.

Siguiendo este paralelismo, lo que nos va a ayudar para ver que el poema es la esencia del habla será pensar en esa retirada que acompaña al desocultar en la apertura de sentido.

\section{El habla en el poema}

"El habla habla en tanto que son del silencio"27. El habla apropiada, el poema, habla en tanto que son del silencio. El son del silencio permite el advenimiento de la Diferencia en la apertura de sentido. El son del silencio acompaña, no antes ni después, al habla, cooriginariamente al habla, ya que el origen es múltiple como hemos visto arriba. El son del silencio, lo no dicho, es lo que resguarda la esencia del habla, y es a lo que los mortales, en tanto que hablantes deben responder y, más aún, corresponder. Porque el son del silencio es una llamada a la que el hablante está destinado a acudir, sin embargo, en el habla cotidiana se desatiende, aunque sigue presente, el son del silencio. Por eso

26 HEIDEGGER, M., "La esencia del habla”, op. cit., p. 148.

27 HeIDEGGER, M., “El habla”. op. cit, p. 22. 
Heidegger irá a buscarlo donde aún se oiga. Por el momento el son del silencio puede quedarse en esta explicación mínima. Si la verdad es desocultación, abrir un claro que al mismo tiempo encubre, el habla es dejar aparecer que al mismo tiempo retiene en lo no dicho, en el son del silencio.

De nuevo hay que destacar que la retirada del ser que opera en el venir a ser en un plano ontológico no es equivalente al son del silencio. Cabe aquí señalar que cuando Heidegger habla de la retirada del ser le interesa destacar su carácter relacional; mientras que el son del silencio tiene un carácter comunicacional en el que reside su singularidad. Puede decirse entonces que tanto el habla y su son del silencio, como el venir a ser y su retirada de ser son momentos de apertura del ser, pero tienen que quedar diferenciados. En De camino al habla Heidegger pone el acento en el aspecto comunicacional del son del silencio y por tanto en el traer a ser como apertura de sentido que tiene lugar en el habla.

El Decir nos en-camina por una región límite entre otras dos, se trata de la región que limita el pensamiento y la poesía, la región de vecindad entre pensamiento y poesía. Sólo aquí están las posibilidades de hacer una experiencia con el habla.

La relación fraternal entre pensar y poetizar no debe ser pensada simplemente como una mezcla de modos de hablar, sino que, si se quiere uno acercar a la relación correspondiente entre ambos debe descubrirse (...) que el poeta nombre en rigor poetizante lo esencial del intento pensante ${ }^{28}$.

Hasta el momento la esencia del habla era retenida por el habla, tanto si se buscaba en el pensamiento como si se hacía en la poesía, de lo que se trata ahora es de buscarla en la mutua vecindad de ambos, siguiendo el camino que concierne a los hablantes. Que poesía y pensamiento sean vecinos significa que habitan próximos el uno al otro, pero es en esa proximidad donde se origina la vecindad en la que los hablantes caminan. "La proximidad que aproxima es el advenimiento apropiador mismo, desde el cual poesía y pensamiento están remitidos a lo propio de su esencia" ${ }^{29}$. Es decir, el estar enfrente la poesía del pensamiento y el pensamiento de la poesía supone una relación limítrofe en la que acontece la apropiación del uno por el otro y del otro por el uno, en la que cada uno se remite a su esencia. Lo que indica Heidegger aquí es que esa región limítrofe que separa y une al pensamiento y la poesía es el Decir; es más: "aquel Decir donde el habla nos dice su esencia" ${ }^{30}$. Ese "nos" se refiere al ser humano, que es tal en tanto que

28 xolocotzl, A., "Poesía y desocultamiento epocal. Aspectos de la relación poesía-claro a partir del pensar histórico de Heidegger". Revista de filosofía, vol. 39, no 118, México, 2007, p. 139.

29 HeIDEGGER, M., "La esencia del habla”, op. cit., p. 145.

$30 \mathrm{lb}$. 
hablante. Se trata de los hablantes que deben recorrer el camino de la región que une y separa pensamiento y poesía; son los únicos que están en condición de hacerlo.

Y esa condición no es otra que el reverso del hablar, esto es, escuchar.

Hablar no es simultáneamente sino previamente un escuchar. Esta escucha del habla precede, también y del modo más inadvertido, a cualquier otra escucha. No sólo hablamos el habla, hablamos desde el habla. Somos capaces de ello solamente porque ya desde siempre hemos escuchado el habla ${ }^{31}$.

Se trata de estar a la escucha de algo que llama, que impele de tal forma que hace al hombre ser lo que es: hablante. El hombre es hablante en tanto que tiene la actitud de estar a la escucha y de responder a la llamada. Una llamada que, sin embargo, no se puede oír como se oye a un amigo en una charla cualquiera, y que a la vez es condición de que se pueda tener esa charla.

Dicho de una vez, el hombre está a la escucha del son del silencio. Es ahí donde el habla nos da su esencia y donde los hombres habitamos, resguardados en la esencia del habla que nos da el cobijo, que nos da la existencia en tanto que hablantes. No obstante, puede que aún no quede clara la relación entre la escucha del son del silencio y que el hombre sea hablante. Dice Heidegger:

El advenimiento apropiador, en su percepción del despliegue de la esencia humana, apropia los mortales en cuanto que los pone en lo propio de lo que se le revela al hombre en el Decir, desde todas partes y hacia lo oculto. La puesta en lo propio del hombre en tanto que "escuchante" del Decir, tiene su rasgo característico en esto que le libera a lo suyo propio, pero solamente para que, en tanto que hablante, o sea, diciente, pueda ir al encuentro y contestar al Decir desde lo que es suyo propio. Y esto es: el resonar de la palabra. El decir de los mortales que viene al encuentro es el responder. Toda palabra hablada ya es siempre respuesta: contra-Decir, decir que viene al encuentro, decir "escuchante" 32.

Se trata aquí de ver que la forma que tiene el hombre de responder, o más bien, de corresponder a la llamada del habla en el son del silencio es el hablar "escuchante". El hombre tiene que corresponder al habla del habla que le sostiene en su seno, y la forma de corresponder es hablando, pero hablando respetando el son del silencio

31 HeIDEGGER, M., "El camino al habla", op. cit. p. 189.

32 Ib. p. 194. 
intrínseco al habla. Tiene que corresponder en forma de agradecimiento, y, como en la antigua Grecia, una de las formas de agradecer a los Dioses era cantando en su honor. El hombre corresponde al habla del habla en forma de un agradecimiento que se resuelve en escuchar el silencio en el poema. Porque el son del silencio, la esencia del habla, es y está en el poema. El poema respeta el son del silencio, el poema consiste en dejar hueco al silencio entre verso y verso, entre estrofa y estrofa, el ritmo del poema radica en las pausas, en el espacio que deja abierto y abriente entre cada verso, ese espacio es el trazo abriente del habla. Porque: "el silencio, al que se suele atribuir el origen del hablar, es ya de por sí un corresponder" ${ }^{\prime 3}$.

No hay mejor manera de mostrar cómo la esencia del habla -el son del silencio- es (y está) ${ }^{34}$ en el poema que viendo cómo Heidegger la encuentra en un poema de Georg Trakl. Así se verá una de las formas en que opera el son silencio. Si bien hay que aclarar antes que Heidegger remarca que la esencia del habla pertenece al Poema único y que "cada poema habla desde la totalidad del Poema único y lo dice cada vez" ${ }^{35}$. El Poema único sería ese poema que el poeta nunca llega a escribir pero que da luz a todos los que de hecho escribe.

Lo que Heidegger hace en El habla en el poema es penetrar, en tanto que portador, en el diálogo del pensamiento con la poesía. Él, un pensador, se acerca a la poesía de Trakl para dejarse encontrar en ella con la esencia del habla. "El diálogo entre pensamiento y poesía evoca la esencia del habla para que los mortales puedan aprender de nuevo a habitar en el habla"36. Sí, de nuevo, porque los mortales han olvidado cómo habitar el habla, han transformado el habla en mero instrumento y no saben ya corresponder.

En esta ocasión Heidegger no elige un poema de Trakl sino que hace un recorrido por varias estrofas de distintos poemas, ya que en última instancia todos remiten al Poema único. Esto supone la complejidad, o tal vez la facilidad, de que no tenemos un solo poema en el que se pueda distinguir lo que pudiera estar diciendo el poeta de lo que está diciendo Heidegger; en cualquier caso, la experiencia con el habla que hay en este texto no tiene relación, como hemos dicho, con algo así como los sentimientos del poeta que deja ver el poema.

\section{3 lb. p. 195.}

34 En alemán, como en otros idiomas, hay una sola palabra para los verbos ser y estar: sein, y en este caso convendría atender a esta duplicidad de significado que en español está escindida en dos palabra.

35 HEIDEGGER, M., "El habla en el poema (1953)", en De camino al habla. op. cit., p. 29. 36 Ib. p. 30. 
Comenzamos con el verso siguiente: “Algo extraño es el alma sobre la tierra" ${ }^{37}$. El alma es así algo extraño porque aún está en camino a, -llamada a, en busca de- su morada en la tierra. Su manera de habitar la tierra es poéticamente: "lleno de mérito, más poéticamente, mora el hombre sobre la tierra" ${ }^{\prime 38}$. El hombre es el compañero de camino del alma. En los poemas de Trakl aparece, sin embargo, la fiera azul: "Si una fiera azul recodara su sendero" 39 .

La fiera azul es el animal, pero no la bestia, que escucha la invocación del poeta. La fiera azul es el hombre, los mortales que caminan junto al extraño, ya que: "el nombre 'fiera azul' denomina mortales que recuerdan al extraño y que quisieran hacer camino con él, a la morada nativa del ser humano" ${ }^{40}$. Buscan la morada nativa, están recorriendo el círculo del que hablábamos al principio, el círculo en el que inevitablemente ya están, pero que tienen que recorrer para volver a aprender a habitar el habla poéticamente. La fiera azul, los mortales, han olvidado el sendero.

"Algo extraño" está llamado, en su camino, al declive, que Trakl llama muerte. Pero no se trata de la muerte como lo es para los mortales, no es la descomposición biológica. "Lo extraño" es algo muerto porque el hombre ha olvidado el sendero para llegar a habitar la tierra en el habla. El alma es algo muerto porque el hombre ha dejado de buscar su modo de morar propio, porque no tiene hogar. La fiera azul es quien puede mirar a lo sagrado. Pero este mirar es entrar en silencio y el hombre ya no entra en silencio. $Y$ sin ese silencio no puede hacerse cargo de la esencia del habla en tanto que dejar aparecer la Duplicidad. La Duplicidad es el advenimiento de lo uno y lo otro, no como discordia, sino siendo uno atravesado por el otro, pero permaneciendo ambos en su esencia propia. La Duplicidad viene a ser aquí el abrirse de la Diferencia.

Mientras que las habladurías encallan en la trivial unanimidad que impone el uno, el decir poético se transforma en registro de lo inasible del ser, sólo deja ver que aquello a que se refiere permanece velado y se manifiesta en tanto que desconocido ${ }^{41}$.

Heidegger está hablando de que la estirpe humana ya no es

37 Citado por HeIDEgGer, M., "El habla en el poema”, op. cit., p. 31.

38 Citado por HEIDEGGER, M., "Hölderlin y la esencia de la poesía (1936)", en Aclaraciones a la poesía de Hölderlin, Alianza Editorial, Madrid, 2005, p. 37.

39 Citado por HeIDEGGER, M., "El habla en el poema”, op. cit., p. 33.

40 HEIDEGGER, M., "El habla en el poema". op. cit., p. 35.

41 agular-Álvarez baY, T., "Pregunta, poesía y el problema de la comunicación en Ser y tiempo" Revista de filosofía, vol 39, Número 118, México, 2007 p.149. 
aquella estirpe cuya duplicidad deja la discordia detrás de sí y que avanza hacia la ternura de una Duplicidad simple, o sea, que es "algo extraño" y que sigue los pasos del extraño42.

Sin silencio que separe y junte sólo hay unidad y esto es el declive de la estirpe humana. En los poemas de Trakl estamos viendo la historia del olvido del hombre de aquello que le es más propio: escuchar el silencio. Por eso el alma es algo muerto.

Pero no acaba aquí. La fiera azul aún sigue al extraño: "cuando los mortales siguen a "algo extraño" llamado al declive, es decir, cuando andan tras el extraño, acceden ellos mismos a la extrañeza; devienen extraños y solitarios" ${ }^{\prime 3}$. Y es que el alma está siendo llevada a "aquel extraño", el otro, el otro de la estirpe humana que se descompone. Esta será la figura en torno a la que giran los poemas de Trakl: el Retraído. El otro del ser humano, al que, sin embargo, está encaminada el alma a la que, en tanto que fiera azul, el hombre sigue. El Decir poético de Trakl es así el Retraimiento.

El Retraído es el fallecido y el demente, "porque está en camino hacia otra parte" ${ }^{44}$, hacia otra a la que el hombre está acostumbrado. Cuando los hablantes siguen al alma, lo más propio de ellos, cogen un sendero distinto del habitual, el sendero que les lleva de vuelta a su hogar, el habla. Trakl nombra al fallecido como Elis: “Oh cuánto tiempo ah, Elis falleciste" ${ }^{\prime 4}$.

"Elis es el extraño llamado al declive"46, la figura de Elis encarna al Retraído que es Ilamado a la muerte prematura, tanto que a veces se le nombra como el no nato. El Retraído representa el fin de la especie corrompida, de la especie humana que ha olvidado el sendero; pero también representa el inicio de la no nata especie. No nata porque aquí nos estamos situando en una concepción distinta del tiempo. La concepción tradicional del tiempo como sucesión de instantes infinitamente divisibles queda fuera del poema. "El verdadero tiempo es el advenimiento de lo que ha sido" ${ }^{47}$; de nuevo el círculo, de nuevo lo que precede a todo venir a ser y que, por ello mismo, ha tenido siempre que ser ya, ahí, en el son del silencio que siempre es ya, en tanto que son, sonido inaudible, oxímoron necesario, porque el origen no es único ni unívoco. Afinemos, una figura retórica se instala en el centro de la apertura misma de sentido que es el habla.

42 HeIDEGGER, M., "El habla en el poema”. op. cit., p. 39.

43 Ib. p. 35.

44 Ib. p. 41.

45 Citado por HeidegGeR, M., "El habla en el poema", op. cit., p. 42.

46 HeIDEGGER, M., "El habla en el poema”. op. cit., p. 42.

47 Ib. p. 44. 
A continuación otro rasgo del Retraimiento: es espiritual. Pero no se trata aquí de lo que se entiende por lo contrario a material, Heidegger remarca que esta es la forma de mirar propia de la estirpe en corrupción. Con "espiritual" se está queriendo hacer mención a lo determinado por el espíritu pero no en sentido metafísico; de hecho,Trakl habla de "la Ilama ardiente del espíritu". Y esto tiene mucha relevancia ya que una llama es lo que ilumina, lo que ilumina un camino que aparece sólo en cuanto que es iluminado. El Retraimiento espiritual conoce el sendero apropiado para que el alma habite la tierra, ilumina el camino hacia lo que los hombres aun consideran extraño.

"Presta tu alma al espíritu, ardiente melancolía"48. El alma se encamina a lo extraño de la mano del espíritu, la esencia del alma es la melancolía porque el sendero la lleva a su hogar, al que añoraba y que a la vez teme. Volver a casa siempre es doloroso, ¿me reconocerán en mi propia casa? ¿se habrán olvidado de mí? El poeta vuelve a la esencia del habla en el poema con el dolor de saberse desterrado de su hogar, de saberse perteneciente a la estirpe corrompida, pero con el ánimo de saberse destinado a habitar poéticamente la tierra:

Sólo arde la melancolía del alma allí donde en su andanza entra en la más vasta amplitud de su esencia propia, es decir, de su esencia caminante. Sucede esto cuando el alma mira hacia el rostro del azul y contempla lo que resplandece en él. En esta contemplación el alma es "el alma grande"49.

La llama del espíritu deja al poeta contemplar el camino, el camino que no es sino su propia esencia en tanto que no hay más remedio que recorrerlo en el habla del habla para poder llegar a donde ya siempre ha estado, pero esta vez hacerlo poéticamente y no solo como mera cháchara.

"Tan dolorosamente bueno y verdadero es lo que vive"50. La contemplación del alma grande es la visión llameante, la visión conducida por el espíritu, la visión que hiere pero que en su reverso deja ser verdaderamente. De nuevo el dolor acompaña al dejar ser: "lo adverso del dolor puede lo que vive desocultar resguardando lo que comparte su presencia, tal como le es propio, esto es, dejar ser verdaderamente" ${ }^{\prime 51}$. El poema resguarda el camino de la estirpe humana hacia su inicio esencial, el que había olvidado y al que se dirige en el poema.

48 Citado por HeIDEgGer, M., "El habla en el poema”, op. cit., p. 47. 49 HEIDEGGER, M., "El habla en el poema”. op. cit., p. 47. 50 Citado por HEIDEGGER, M., "El habla en el poema”, op. cit., p. 50. 51 HEIDEGGER, M., "El habla en el poema”. op. cit., p. 48. 
Lo que Heidegger localiza es que el poema ya habla siempre desde el estar-en-camino del Retraimiento. El poema mismo es ponerse en camino a la esencia del habla, el poema es el extraño sobre la tierra que busca habitarla. "En el esplendor conmovedor que brilla desde el lugar del Poema único, brota aquella ola que mueve el decir poético hacia su habla"52.

El poema se hace cargo del Retraimiento, y le hace hueco en él, lo cobija como aquel que se va y que en su irse abre el claro de sentido. De todas las acepciones que tiene en español la palabra retraer, la más acertada aquí sería la de encoger un órgano o miembro del cuerpo para que quede oculto. En el poema aparece el retraerse del habla en el son del silencio, esto es, la esencia del habla. El Retraimiento puede verse entonces como una forma de operar el son del silencio, una forma en la que el hombre puede hacerse cargo de él y corresponder así al habla.

\section{Conclusión}

El objetivo de este trabajo ha sido mostrar, en los escritos de Heidegger de los años 50, la dilucidación de la esencia del habla en el poema. El punto de partida ha sido la renuncia a entender el habla como mero instrumento para hacerse cargo de la esencia del habla de un modo originario. Heidegger plantea esta tarea como el recorrer un camino. Se trata de un camino peculiar, ya que él mismo es la cuestión que se trata de iluminar. Así, los hombres, en tanto que hablantes, serán los encargados de recorrer el camino que lleva a la esencia del habla, siendo el camino el habla misma.

Tomando como frase rectora "la esencia del habla: el habla de la esencia" ${ }^{53}$, hemos visto que el habla deviene esencia en tanto que en ella se abre el sentido, se da una apertura en el claro en el que los entes vienen a ser. El habla aparece entonces como origen de sentido. No origen unitario sino plural, y fracturado en sí mismo. Por eso el claro de sentido es un espacio abierto, una raja en el ser. El habla es apertura de sentido, donación de ser y por ello un salto del no ser al ser, esto conlleva el dolor del desequilibrio, la falta de un suelo estable, la falta de un origen sustancial que consuele.

La fractura en el origen, la no completitud, hace referencia a la Diferencia gracias a la cual las cosas son lo que son. La Diferencia como fractura y relación en un origen desagarrado. La Diferencia que sostiene la apertura de sentido se deja oír en el son del silencio que está siempre con el habla, es cooriginario al habla. El son del silencio se

52 Ib. p. 57.

53 HEIDEGGER, M., “La esencia del habla”, op. cit., p. 148. 
ha revelado como constitutivo al habla y, por tanto, como constitutivo a la apertura de sentido. Para atender a la esencia del habla hay que hacerse cargo del son del silencio. Lo que se trataba de mostrar era cómo los hablantes corresponden al son del silencio en el poema y no en el habla cotidiana.

En el poema los mortales corresponden al son del silencio escuchándolo. El silencio entre verso y verso, que marca un ritmo no audible. Pero también el eco de lo no dicho en el poema, el eco del poema único que resuena en cada poema concreto. Heidegger hace el ejercicio de prestar oídos a los poemas de Trakl. En ellos se escucha la historia de la estirpe humana corrompida, que ha dejado de atender a la esencia del habla, y la historia del alma errante que busca su morada en el mundo. Cuando el hombre sigue al alma perdida, ambos se dirigen a lo que les es más propio, a su esencia misma. Porque el hombre, en tanto que hablante, está llamado a dilucidar la esencia del habla.

\section{Bibliografía}

aguilar-Álvarez bay, T. "Pregunta, poesía y el problema de la comunicación en Ser y Tiempo". Revista de filosofía, vol. 39, no 118. México, 2007.

HeIDegger, M. Aclaraciones a la poesía de Hölderlin. Madrid, Alianza, 2005.

HeIDegGer, M. Caminos de bosque. Madrid, Alianza, 2010.

HEIDEGGER, M. De camino al habla. Barcelona, Serbal, 2002.

HEIDEGGER, M. Hitos. Madrid, Alianza, 2000.

VATTIMO, G. Introducción a Heidegger. Barcelona, Gedisa, 1998.

xolocotzi, A. "Poesía y desocultamiento epocal. Aspectos de la relación poesía-claro a partir del pensar histórico de Heidegger". Revista de filosofía, vol. 39, no 118. México, 2007. 